\title{
Chronic Prostatitis (CP) in Atlas Shepherd Dog: A Case-Control Study
}

\author{
Ahmed Boucif*, Khadidja Madani, Aboud Boulkaboul and Khaled Slimani \\ Laboratory of farm animal reproduction, Institute of veterinary sciences, University Ibn Khaldoun, BP 78, Tiaret 14000, Algeria \\ ${ }^{*}$ Corresponding author: Ahmed Boucif, Laboratory of farm animal reproduction, Institute of veterinary sciences, University Ibn Khaldoun, BP 78, Tiaret 14000, Algeria, \\ Tel: +213-46425688; E-mail: moussa7014@yahoo.fr
}

Received date: February 11, 2015, Accepted date: April 26, 2015, Published date: April 30, 2015

Copyright: (C) 2015 Boucif $A$, et al. This is an open-access article distributed under the terms of the Creative Commons Attribution License, which permits unrestricted use, distribution, and reproduction in any medium, provided the original author and source are credited.

\begin{abstract}
This study reports the clinical, ultrasonographic and bacteriological findings from dog with chronic prostatitis (CP). A Berger de l'Atlas dog ten years old, suffering from a urinary problem was presented to the canine clinical pathology of Tiaret veterinary science Institute for consultation. The digital rectal examination (DRE) was the first diagnostic test used for CP screening. The classic ellipsoid formula was adequate for determining the prostate volume. Clinical examination of the prostate based on rectal palpation and ultrasound detected prostatic hypertrophy with no signs of pain. Urine and prostatic fluid aspirated under ultrasound guidance are clouding. The estimated increase in the prostate volume measured with abdominal ultrasound was $25.04 \mathrm{~cm}^{3}$. The culture of urine and prostatic fluid revealed presence of Escherichia coli. No complications were observed after drainage, and clinical signs in dog.
\end{abstract}

Keywords: Berger de l'Atlas Dog; Prostate; Hematuria; Results and Discussion Ultrasonography; Escherichia coli

Urine analysis revealed turbid, foul odour, red color urine and

\section{Introduction}

Prostatitis is the second most common canine prostatic disorder, and can be acute or chronic. This may be caused by infective agents. Only one-third of cases of prostatitis are caused by a single bacterial agent and the others show a mixed growth of several infectious agents or no bacteria, depending on the study $[1,2]$. The chronic prostatitis (CP) in dogs is poorly documented clinically. The main diagnostic techniques for prostatic diseases are history, physical and laboratory examinations, radiography, ultrasonography, seminal cytology and bacteriology. Ultrasonography is the method of choice when investigating the prostate, imaging the size of the gland as well as the homogenicity of the parenchyma [3,4]. The present case was a chronic prostatitis in Algeria Atlas Shepherd Dog.

\section{Case Presentation}

A ten year old intact male Atlas Shepherd Dog, weighing $18 \mathrm{~kg}$ was presented to canine clinical Pathology, Institute of Veterinary Science, University Ibn Khaldoun, with a history of hematuria, temperature of $38.6^{\circ} \mathrm{C}$ and foul-smelling urine. Escherchia coli (E.coli) isolated from both prostatic fluid and urine. Cultural examination showed profuse growth of organisms identified as $E$. coli on the basis of cultural (MacConkey, Agar) and biochemical characteristics (Api, 20E). The measurement of the volume of the prostate (VP) in our case was made at the base of the formula of the ellipsoid according to Kamoplatana et al [5].

$\mathrm{L}=$ length (in $\mathrm{cm}$ ) of the prostate out of longitudinal section, $\mathrm{H}=$ average $(\mathrm{in} \mathrm{cm}$ ) heights out of sections transverse and longitudinal; $\mathrm{I}=$ width $($ in $\mathrm{cm}$ ) of the prostate out of cross-section.

$$
V_{p}=\frac{4}{3} \times \pi \times \frac{L}{2} \times \frac{1}{2} \times \frac{H}{2}=0.523 \times L \times 1 \times H
$$

haematuria. A digital rectal examination (DRE), prostatic is asymmetrical, hard texture with irregular surface. However its exam did not involve demonstrations of pain.

The prostate volume, calculated according to formula ultrasound measurements of the ellipsoid was estimated to $25.04 \mathrm{~cm}^{3}$. Ultrasound examination of the prostate (Figure 1) showed an increase of its volume with a heterogeneous texture parenchyma and presence of several cavities hypoechoic prostate. In this review we have not detected a bladder or kidney abnormality. The basis of diagnosis was clinico-bacteriological examination, preponderance of E.coli.

In male dog, there are many diseases that may affect the prostate gland whose prostatitis are generally, observed in the whole male dogs [6,7].

Krawiec and Heflin [8] reported that chronic prostatitis represents up to $80 \%$ of cases observed in uncastrated male dogs with an average of 8.2 years at diagnosis.

Numerous published studies have described the specificity of various imaging techniques for detection of CP. According to Wilson [9], the age distribution was $8 \%$ for dogs over 10 years and $<1 \%$ for dogs under 4 years of age; Non-castrated dogs represent the vast majority of cases, but neutered dogs may also have prostatic tumours and infections.

Prostatic syndrome is generally recognizable clinically by certain signs, such as difficulties of urine excretion and haematuria that are most often observed with abscesses, benign hypertrophy and tumors [8]. However, to make a definitive diagnosis, clinical examination should be supplemented by further investigations.

During digital rectal examination in the case of a suspected chronic prostatitis, prostate is not painful, but according to the degree of fibrosis secondary to inflammation, it can be asymmetrical and 
Page 2 of 2

hypertrophied when there is another concomitant prostate affection such as benign prostatic hypertrophy $[10,11]$.

However, there is no pathognomonic picture of chronic prostatitis where ultrasound appearance of lesions is often non-specific and similar to that of a hyperplasia, abscesses or tumors [5]. But as the inflammation progresses, modified ultrasound image becomes more specific. An increase in size associated with heterogeneous echogenicity is frequently observed; which is in agreement with ultrasound results in the present case.

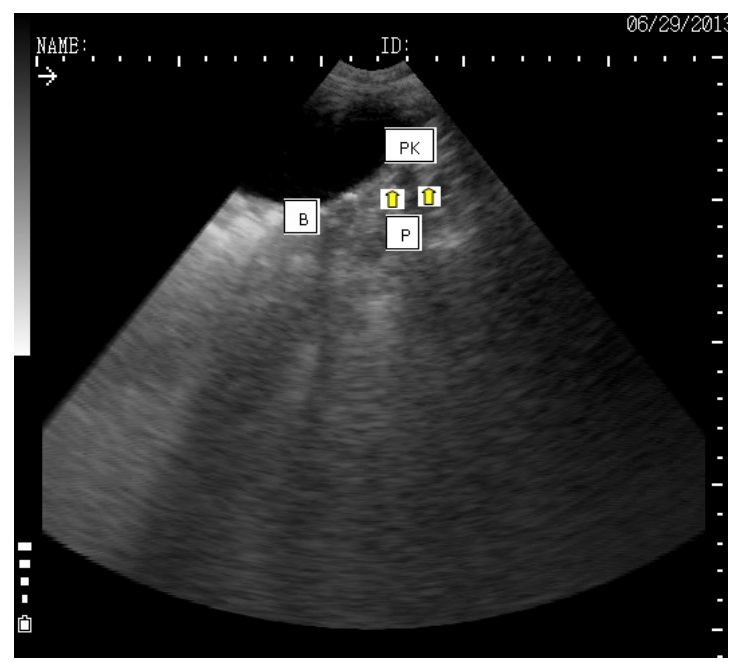

Figure 1: Echography showed a parenchyma of a heterogeneous texture and presence of several cavities prostate sufferers hypoechogenes with a normaly vesical and renal. P: Prostate; PK: Prostatic kystic; B: Normal blader.

According to Kamoplatana [5], chronic prostatitis may be a complication of benign prostatic hyperplasia, which is the cause of progressive change in prostate gland symmetry.

On the other hand, Forrester et al. [10] reported that the prevalence of prostate tumors is $0.29 \%$ to $0.6 \%$ and $3.5 \%$ to $15 \%$ in dogs with prostatic disease. Castration and age appeared as risk factors with castrated dogs having 4.34 folds higher risk of developing prostate tumor than intact dogs $[7,12]$. Since the presented dog is uncastrated with absence of pain, suspicion of a tumor in this case is to be excluded.

Chronic bacterial prostatitis is very common condition that causes recurring infections in the prostate and results in swelling, inflammation, and frequent urinary tract infections.

Studies suggest that an E.coli bacterial prostatitis was experimentally induced in dogs to determine the effect of castration on chronic bacterial prostatitis [13]. In a research by Palmieri et al. [6], E. coli isolates obtained from 11 cases presenting with haematuria (6.7\%), acute uncomplicated cystitis and urinary incontinence, respectively. A case of CP was diagnosed in atlas shepherd dog from Algeria. Digital rectal excamination, ultrasound and clinic-bacteriological parameters were studied in detail.

\section{Conclusion}

Any prostatic syndrome requires a complete physical exam of the genitourinary tract. Nevertheless, this examination must be supplemented by complementary measures in order to lead to a diagnosis of certainty. Ultrasonography remains always the examination of imagery of choice in order to detect the abnormal state of the prostatic parenchyma, supplemented by a bacteriological examination. This study, carried out at the institute of veterinary sciences, will enable us to use other thorough measurements and antibiotherapy agents in the future in order to confirm the diagnosis carried out in front of any affection prostate sufferer.

\section{Acknowledgement}

The authors thank the personnel for the service of microbiology of the institute of veterinary sciences for their assistance with the realization of the bacteriological examination.

\section{References}

1. Barsanti JA (1997) Disease of the Prostate Gland. Proceeding of the Annual Meeting of the Society for Theriogenology, pp. 72-80.

2. Ling GV, Branam JE, Ruby AL, Johnson DL (1983) Canine prostatic fluid: techniques of collection, quantitative bacterial culture, and interpretation of results. J Am Vet Med Assoc 183: 201-206.

3. Lévy X, Maurey C, Fontaine E, Fontbonne A (2006) Comparative Evaluation of five Different Techniques to Diagnose Prostatic Infection in the Dog. Proceeding of the 5th EVSSAR meeting, pp. 319.

4. Günzel-Apel AR, Möhrke C, Poulsen Nautrup C (2001) Colour-coded and pulsed Doppler sonography of the canine testis, epididymis and prostate gland: physiological and pathological findings. Reprod Domest Anim 36: 236-240.

5. Kamolpatana K, Johnston GR, Johnston SD (2000) Determination of canine prostatic volume using transabdominal ultrasonograpohy. Vet Radiol Ultrasound 41: 73-77.

6. Palmieri C, Lean FZ, Akter SH, Romussi S, Grieco V (2014) A retrospective analysis of 111 canine prostatic samples: histopathological findings and classification. Res Vet Sci 97: 568-573.

7. Root-Kusritz MV, Klausner JS (2000) Prostatic diseases. In: Ettinger SJ, Feldman EC (eds.) Textbook of Veterinary Internal Medicine. Diseases of the Dog and Cat. WB Saunders Company, Philadelphia.

8. Krawiec DR, Heflin D (1992) Study of prostatic disease in dogs: 177 cases (1981-1986). J Am Vet Med Assoc 200: 1119-1122.

9. Wilson JD (2011) The critical role of androgens in prostate development. Endocrinol Metab Clin North Am 40: 577-590, ix.

10. Forrester S D, BJ Purswell (1997) Diseases of the prostate. In: Leib MS, Monroe WE (eds.) Practical Small Animal Internal Medicine. WB Saunders Company, Philadelphia.

11. Mukaratirwa S, Chitura T (2007) Canine subclinical prostatic disease: histological prevalence and validity of digital rectal examination as a screening test. J S Afr Vet Assoc 78: 66-68.

12. Teske E, Naan EC, van Dijk EM, Van Garderen E, Schalken JA (2002) Canine prostate carcinoma: epidemiological evidence of an increased risk in castrated dogs. Mol Cell Endocrinol 197: 251-255.

13. Cowan LA, Barsanti JA, Crowell W, Brown J (1991) Effects of castration on chronic bacterial prostatitis in dogs. J Am Vet Med Assoc 199: 346-350. 